\title{
Influence of prophylactic photochemotherapy on incidence of relapse of psoriasis cleared initially with dithranol
}

\author{
JANET M MARKS, C M LAWRENCE, M CORBETT, P COBURN, S PARKER, SAM SHUSTER
}

\begin{abstract}
Forty one patients whose psoriasis cleared with dithranol were given prophylatic photochemotherapy with psoralens and ultraviolet $A$ once a week. With life table analysis the chance of remaining in remission for 16 months was shown to be $42 \%$ for these patients, compared with $13 \%$ for a group of patients who were not given prophylactic photochemotherapy.
\end{abstract}

\section{Introduction}

A randomised controlled trial of photochemotherapy (psoralens and ultraviolet $\mathrm{A}$ ) in chronic plaque psoriasis showed that clearance takes a mean of 34 days' treatment $^{1}$ and that prophylactic photochemotherapy maintained after the rash has been cleared increases the chance of a patient remaining in remission. ${ }^{2}$ As Ingram's regimen of treatment with dithranol takes only 20 days to clear psoriasis ${ }^{1}$ a possible way of managing chronic psoriasis might be to clear it with dithranol and then give prophylactic photochemotherapy; we investigated this possibility in 41 patients.

\section{Patients, methods, and results}

Over a two year period, when about 300 inpatients were treated for psoriasis in our unit, we investigated 41 patients in 43 attacks ( 41 of chronic plaque and two of guttate psoriasis). They had agreed to

\footnotetext{
University Department of Dermatology, Royal Victoria Infirmary, Newcastle upon Tyne NE1 4LP

JANET M MARKS, DM, FRCP, senior lecturer in dermatology and consultant dermatologist

C M LAWRENCE, MRCP, senior registrar

P COBURN, MRCP, research registrar

S PARKER, MB, BS, research registrar

SAM SHUSTER, PHD, FRCP, professor of dermatology

Welsh National School of Medicine, Cardiff

M CORBETT, MB, BS, lecturer in dermatology

Correspondence to: Dr C M Lawrence.
}

receive prophylaxis with psoralens and ultraviolet $\mathrm{A}$ after their rash had been cleared with Ingram's dithranol regimen. The usual contraindications to photochemotherapy were applied, ${ }^{1}$ and only exceptionally did we approach anyone under 30 ; in addition, some patients declined prophylaxis for their own reasons. The incidence of relapse was compared with that in the 76 patients in our previous study, whose psoriasis had been cleared with dithranol and subse-

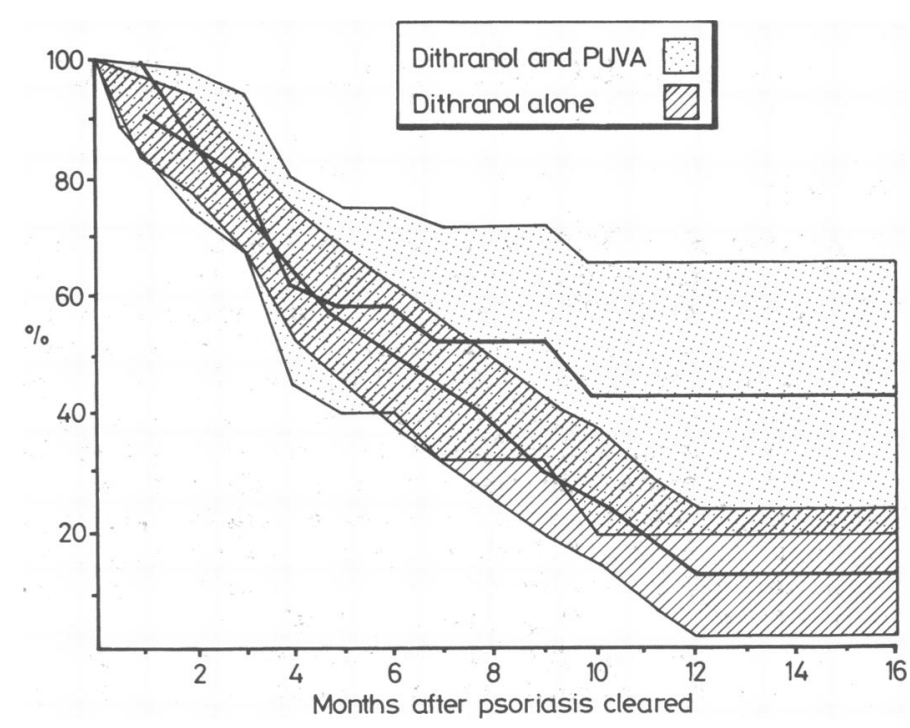

Estimated probability of remaining in remission for patients treated with dithranol followed by psoralens and ultraviolet A (PUVA) and those treated with dithranol alone. Shaded areas represent 2 SEM.

quently left untreated. ${ }^{2}$ Relapse was considered to have occurred if the area of skin affected reached half the area that had been affected before dithranol was started.

Psoralens and ultraviolet A were started within seven days after the psoriasis was cleared and were given according to our previous regimen once a week. ${ }^{2}$ The starting dose of ultraviolet $\mathrm{A}$ for prophylaxis depended on skin type $\left(\mathrm{I}, 1.5 \mathrm{~J} / \mathrm{cm}^{2} ; \mathrm{II}, 2.5 \mathrm{~J} / \mathrm{cm}^{2} ; \mathrm{III}, 3.5\right.$ $\mathrm{J} / \mathrm{cm}^{2} ; \mathrm{IV}, 4 \cdot 5 \mathrm{~J} / \mathrm{cm}^{2}$ ). If new lesions appeared the dose was increased by $1 \mathrm{~J} / \mathrm{cm}^{2}$ at the next treatment; this increase was halted if the skin cleared or if burning occurred. 
As before we used the life table method of analysis, ${ }^{3}$ whereby the number of patients in remission at the start of each month is expressed as a percentage of those having treatment in that month. This allows for the analysis of data from patients entering and leaving the study at different times.

The 43 patients under investigation were followed up for from one to 26 months (mean (SEM) $4 \cdot 8(0 \cdot 7)$ months). During this time 15 relapsed, after a mean of $3.6(0.6)$ months, and five withdrew. The remaining $23(53 \%)$ had not relapsed after a mean of $6.3(1 \cdot 2)$ months. The 75 control patients were followed up for four to 16 months (mean 5.4 (0.4) months). The $23(31 \%)$ who did not relapse were followed up for a mean of $8.8(1.0)$ months. The figure shows the chances of patients in these two groups remaining in remission. At 16 months the chance of being in remission was $42 \%$ for patients in this study compared with $13 \%$ for the control patients; the difference between the curves was significant $(p<0.03)$. Our analysis finished at 16 months, though one patient in this study continued for 26 months without relapsing.

\section{Discussion}

The results show that relapse of chronic plaque psoriasis treated with dithranol can be postponed or prevented by giving psoralens and ultraviolet $A$ once a week. In our study of patients given psoralens and ultraviolet $\mathbf{A}$ as treatment and then as prophylaxis we found that there was little difference in the incidence of relapse between treatment given weekly and once every three weeks, ${ }^{2}$ so it is possible that if the frequency of treatment was reduced the dose of ultraviolet A given after treatment with dithranol could be reduced below the $10 \cdot 6$ $\mathrm{J} / \mathrm{cm}^{2} / \mathrm{month}$ that we used.

The $42 \%$ chance our patients had of remaining in remission at 16 months is not as good as the $80 \%$ chance that we found in patients given psoralens and ultraviolet $\mathrm{A}$ as both treatment and prophylaxis. ${ }^{2}$ A possible explanation is that in the previous study the starting prophylactic dose of ultraviolet $\mathrm{A}$ was the same as the dose at the end of the clearance regimen, which was roughly three times that given initially to the present patients, whose dose was according to skin type.

We are grateful to the Newcastle health authority research fund for a grant and to Dr Vella Briffa for further details of some of the patients in a previous joint study.

\section{References}

${ }^{1}$ Rogers S, Marks J, Shuster S, Briffa DV, Warin AP, Greaves MW. Comparison of photochemotherapy with dithranol in the treatment of chronic plaque psoriasis. Lancet 1979; i:455-8.

${ }^{2}$ Briffa DV, Greaves MW, Warin A, Rogers S, Marks J, Shuster S. Relapse rate and long-term management of plaque psoriasis after treatment with photochemotherapy and dithranol. Br Med F. 1981 ;282: 937-40.

${ }^{3}$ Colton T. Longitudinal studies and the use of the life table. Statistics in medicine. Boston: Little, Brown and Co, 1974:237-50.

(Accepted 7 November 1983)

\title{
Diabetic hypertriglyceridaemia and related 5' flanking polymorphism of the human insulin gene
}

\author{
N I JOWETT, L G WILLIAMS, G A HITMAN, D J GALTON
}

\begin{abstract}
A polymorphic DNA sequence was studied on the $5^{\prime}$ flanking region of the human insulin gene in relation to diabetic lipaemia. The genotype frequencies in a control population $(n=52)$ were homozygous $L$ $6 \%$, heterozygous $54 \%$, and homozygous S $40 \%$. Corresponding genotype frequencies in a hypertriglyceridaemic group $(n=74)$ were $18 \%, 66 \%$, and $16 \%\left(p<0.01 ; \chi^{2}\right.$ test $)$. When the hypertriglyceridaemic patients were divided on the basis of glucose tolerance the corresponding genotype frequencies in the diabetic subgroup $(n=23)$ were $39 \%$, $52 \%$, and $9 \%$ compared with $0 \%, 74 \%$, and $26 \%$ in the non-diabetics $(\mathbf{n}=34)\left(\mathbf{p}<0.001 ; \chi^{2}\right.$ test).

These findings suggest that the homozygous $L$ genotype may confer susceptibility to diabetic hypertriglyceridaemia.
\end{abstract}

\section{Introduction}

Hypertriglyceridaemia, defined as a fasting serum triglyceride concentration exceeding $2 \mathrm{mmol} / 1(177 \mathrm{mg} / 100 \mathrm{ml})$, is a heterogeneous group of disorders that occurred in more than $10 \%$ of men in a British population. ${ }^{1}$ The aetiology of the common forms of the disorder is poorly understood but is generally considered to include an interaction between genetic and environmental factors. In rare instances the disease may be due to a single gene defect involving the synthesis of either lipoprotein lipase or its peptide activator apoprotein C-II. ${ }^{2}{ }^{3}$ In the common forms of hypertriglyceridaemia it is possible that several gene variants confer susceptibility to the effects of environmental factors such as excess dietary carbohydrate or alcohol. In support of this view we have recently observed a polymorphic DNA locus close to the apoprotein A-1 gene which appears to segregate with patients who have hypertriglyceridaemia. ${ }^{4}$ In view of the probable polygenic nature of this disorder we are studying other gene or gene associated variants which may associate with the disease.

Insulin is one of the major hormones that influences the circulating concentrations of plasma triglyceride. It is required for maintaining the activity of lipoprotein lipase in tissues, which is central in the clearance of plasma triglyceride ${ }^{5}$; and in insulin resistant or deficient states hypertriglyceridaemia commonly results. ${ }^{6}$ There is also a close relation between hyperglycaemia and hypertriglyceridaemia when the secretion or action of insulin is impaired.

The human insulin gene is located on the short arm of chromosome $11 .{ }^{7}$ At one end of the gene $\left(5^{\prime}\right)$ is a highly variable
Department of Medicine, St Bartholomew's Hospital, London EC1A 7BE

N I JOWETT, MB, MRCP, honorary senior registrar

L G WILLIAMS, PHD, senior biochemist

G A HITMAN, MB, MRCP, honorary senior registrar

D J GALTON, MD, FRCP, consultant physician

Correspondence to: Dr D J Galton. 